\title{
PENYULUHAN MESIN PENIRIS MINYAK KERIPIK PISANG
}

\author{
Moh. Mufti ${ }^{*}$, Edi Santoso ${ }^{2}$, M. Sahrul Maulana ${ }^{3}$ \\ 1,2,3 Universitas 17 Agustus 1945, Jl. Semolowaru 45, Surabaya \\ *Penulis korespondensi; email: mufti@untag-sby.ac.id
}

\begin{abstract}
Abstrak: Buah pisang adalah salah satu buah potensial di Desa Galengdowo, yang dapat berbuah sepanjang tahun. Hasil panen pisang mencapai \pm 10 ton / tahun. Selama panen massal, terutama mangga, harga pisang turun sehingga petani mengalami kerugian besar. Akibatnya, solusi alternatif diperlukan untuk mengatasi masalah ini, yaitu dengan mengolah pisang menjadi keripik pisang, yang telah diprakarsai oleh beberapa kelompok pengrajin keripik pisang di Desa Galengdowo. Masalah yang dihadapi oleh pengrajin adalah kapasitas produksi yang rendah, karena masih menggunakan metode manual, terutama terkait dengan pengeringan minyak dari wajan dan penimbangan keripik pisang. Mayoritas penduduk adalah petani \& peternak sapi perah dengan tingkat pendidikan rendah (rata-rata lulusan SMP dan SMA). Dengan penyuluhan dan bantuan 1 unit TTG mesin spinner peniris minyak keripik pisang kapasitas $5 \mathrm{~kg}$ dan 1 unit timbangan digital dari tim, para pengrajin akan dapat meningkatkan kapasitas produksinya sehingga manfaat yang diperoleh akan lebih besar, dengan produksi keripik pisang yang enak, kering dan renyah, yang dapat diproduksi terus menerus. Sehingga akan dapat meningkatkan pendapatan pengrajin keripik pisang di Desa Galengdowo.
\end{abstract}

Kata kunci: Keripik pisang; mesin spinner; kapasitas produksi.

\begin{abstract}
Banana fruit is one of the potential fruits in Galengdowo Village, which can bear fruit throughout the year. Banana yields reach \pm 10 tons / year. During the mass harvest, especially mangoes, the price of bananas dropped so that the farmers experienced a substantial loss. As a result, an alternative solution is needed to deal with this problem, namely by processing bananas into banana chips, which have been initiated by several groups of banana chips craftsmen in Galengdowo village. The problem faced by the craftsmen is the low production capacity produced, because it still uses manual methods, mainly related to the draining of the oil from the frying pan and the weighing of the banana chips. The majority of the population there are farmers \& dairy farmers with a low level of education (average junior and senior high school graduates). With the counseling and assistance of 1 unit of TTG banana chips spinner machine capacity of $5 \mathrm{~kg}$ and 1 unit of digital scales from the team, the craftsmen will be able to increase their production capacity so that the benefits obtained will be greater. With the production of delicious, dry and crispy banana chips, which can be produced continuously. So that it will be able to increase the income of the banana chip craftsmen in Galengdowo Village.
\end{abstract}

Keywords: Banana chips; spinner machine, production capacity.

\section{PENDAHULUAN}

Keripik pisang merupakan salah satu makanan tradisional yang digemari oleh masyarakat Indonesia pada umumnya, mulai dari anak-anak sampai dengan orang tua. Keripik pisang merupakan salah satu terobosan yang dapat dibuat dari jenis keripik yang ada saat ini, bahan bakunya terbuat dari buah pisang. Pisang adalah merupakan salah satu jenis buah yang dihasilkan di desa Galengdowo, dengan hasil produksi sebanyak 10 ton per tahun. Galengdowo adalah sebuah desa di
Kecamatan Wonosalam Kabupaten Jombang- Jawa Timur. Desa Galengdowo terdiri dari 5 dusun yaitu Dusun Wates, Sanggar, Plumpung, Galengdowo dan Dusun Pangajaran. Masing-masing dusun dipimpin oleh Kepala Dusun. Desa Galengdowo terletak di dataran tinggi $( \pm 700 \mathrm{~m}$ diatas permukaan laut) di sebelah tenggara Kota Jombang di lereng Gunung Anjasmoro. Mayoritas penduduknya adalah petani dan peternak sapi perah. Jumlah penduduk sebanyak 3.031 jiwa, dengan 1069 KK.

Desa Galengdowo yang letaknya di dataran tinggi tersebut, kondisi tanahnya sangatlah subur, 
sehingga tanaman apapun yang ditanam di desa itu akan dapat tumbuh dengan subur, termasuk tanaman pisang. Sehingga keadaan tersebut mengingatkan kita pada lagu dari kelompok penyanyi "Koesplus" yang berjudul "Kolam Susu" yang syairnya diantaranya berbunyi "orang bilang tanah kita tanah surga, tongkat kayu dan batu jadi tanaman“. Tanaman pisang adalah merupakan salah satu tanaman favorit produktif yang terdapat di desa itu, yang berbuah sepanjang tahun. Pisang yang dihasilkan di Desa Galengdowo, sangatlah istimewa dimana buahnya mempunyai ukuran besar serta rasanya yang manis (kualitasnya sangat baik). Selain kualitas buah pisang yang sangat baik, hasil produksi buah pisang di Desa Galengdowo juga melimpah.

Kualitas buah pisang yang sangat baik itu, menyebabkan harga jual keripik pisang juga cukup tinggi, mencapai harga Rp.60.000,-/kg. Sedangkan kendala dari pengrajin keripik pisang yang dihadapi saat ini adalah rendahnya produksi yang dihasilkan, sebagai akibat dari proses penirisan dan penimbangan yang dilakukan secara manual sehingga butuh waktu yang lama untuk proses ini. Padahal permintaan pasar cukup banyak.

Diharapkan dengan melakukan pengabdian masyarakat melalui penyuluhan mesin spinner kepada para pengrajin keripik pisang di Desa Galengdowo, serta memberikan bantuan 1 unit mesin spinner (peniris minyak) dan 1 unit timbangan digital dari program ini, akan dapat menyelesaikan masalah yang dihadapi oleh para pengrajin keripik pisang. Produksi keripik akan dapat ditingkatkan, produk keripik jadi lebih kering dan renyah, sehingga keuntungan (profit) yang akan diperoleh jadi lebih meningkat.

TTG Mesin spinner peniris minyak adalah mesin peniris minyak hasil dari penggorengan keripik pisang, yang dilakukan dengan memutar drum penyaring minyak yang terdapat dibagian dalam mesin peniris, menggunakan motor listrik dengan konsumsi daya yang relatif kecil sebesar 0,25 HP. Drum penyaring diputar melalui poros pemutar yang dihubungkan dengan pulley melalui sabuk (belt) dari pulley motor ke pulley drum penyaring. Pada saat drum penyaring berputar (berotasi), maka gaya centrifugal yang terjadi pada drum akan melempar keripik pisang yang bercampur dengan minyak goreng ke bagian dinding drum penyaring yang permukaannya berlubang. Melalui lubang-lubang drum penyaring tersebut, minyak dengan sendirinya akan terlempar keluar menuju drum cover penampung minyak, yang selanjutnya minyak akan dikeluarkan melalui saluran keluar. Setelah diputar beberapa saat, maka dengan sendirinya minyak akan tertiris dan keripik pisang yang dihasilkan akan jadi kering, renyah dan enak.

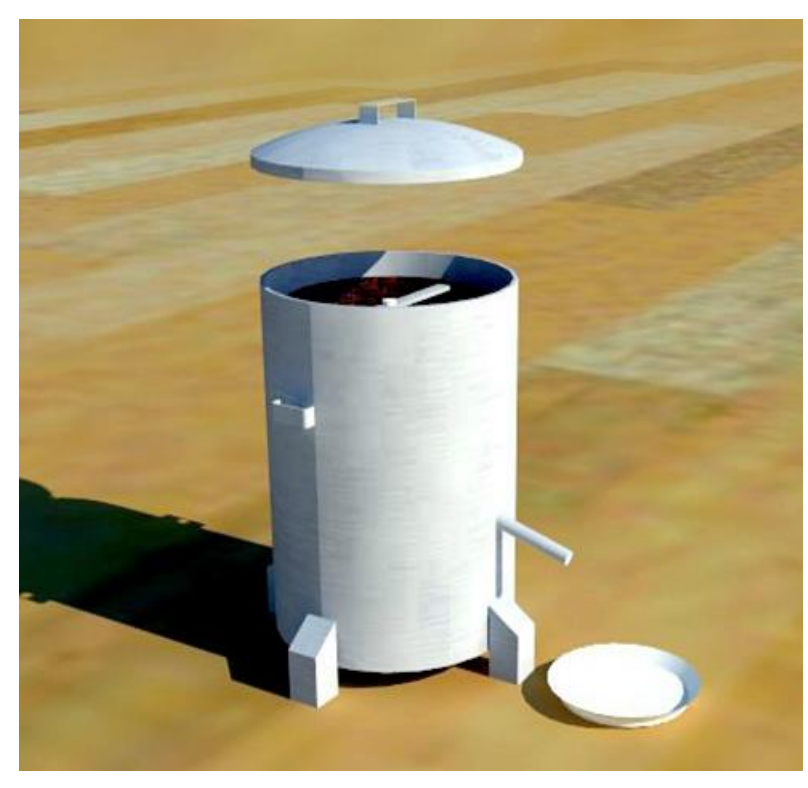

Gambar 1. Mesin Spinner Peniris Minyak

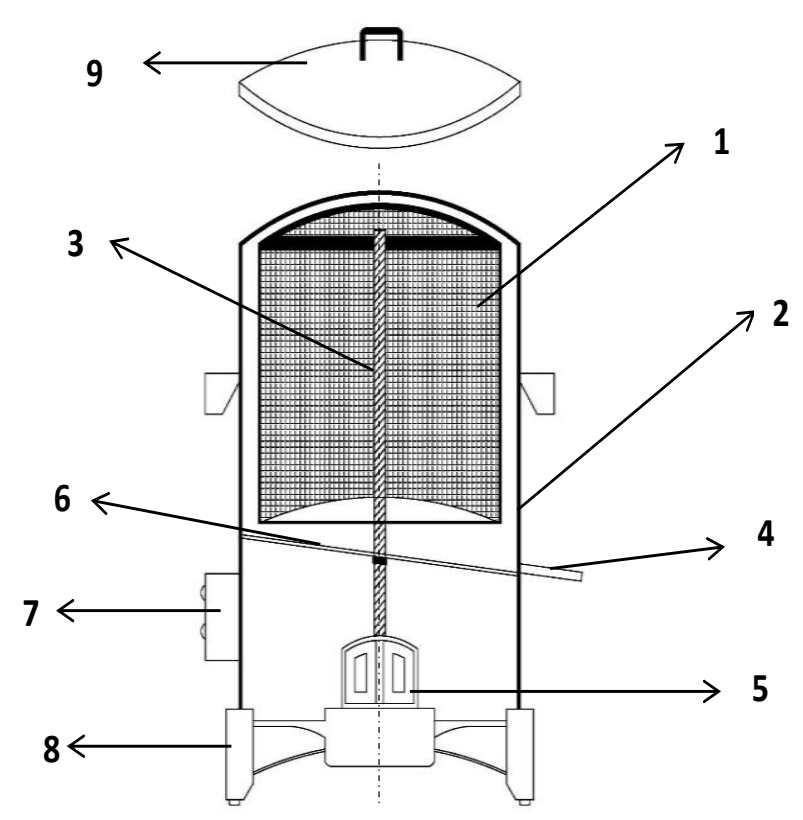

Gambar 2. Penampang Potongan Mesin Spinner

Keterangan:

1. Drum penyaring minyak

2. Cover penutup mesin

3. Poros pemutar drum

4. Saluran keluar minyak goreng

5. Motor listrik pemutar poros

6. Drum cover penampung minyak

7. Saklar on-off

8. Kaki mesin

9. Penutup mesin

\section{METODE PELAKSANAAN}

Metode pengabdian masyarakat, melalui kegiatan penyuluhan mesin spinner keripik pisang ini, ditujukan bagi kelompok pengrajin keripik 
pisang di Desa Galengdowo, metode pelaksanannya dilakukan dengan melalui tahapan seperti berikut:

1. Observasi/survei lapangan, berujuan untuk melihat secara langsung di lapangan, masalah yang dihadapi oleh kelompok pengrajin keripik pisang, melalui kunjungan lapangan.

2. Melakukan diskusi antara tim dengan kelompok pengrajin, maupun diskusi antar anggota tim, dalam rangka untuk mencari solusi guna menyelesaikan masalah yang dihadapi oleh para pengrajin keripik pisang.

3. Menyusun program kegiatan dalam rangka untuk membahas dan menentukan solusi apa yang akan dilakukan, dalam rangka menyelesaikan masalah yang dihadapi oleh kelompok pengrajin keripik pisang.

4. Dari hasil diskukusi dan analisa permasalahan yang dihadapi oleh kelompok pengrajin keripik pisang, ditentukan bahwa solusinya adalah memberikan penyuluhan mesin peniris minyak keripik pisang, sekaligus memberikan bantuan 1 unit mesin TTG peniris minyak keripik pisang dan 1 unit timbangan digital kepada pengrajin, untuk mempercepat proses produksi.

5. Melaksanakan program kegiatan penyuluhan kepada seluruh pengrajin keripik pisang, bertempat di salah satu rumah pengrajin keripik pisang Desa Galengdowo.

6. Memberikan bantuan 1 unit mesin spinner dan 1 unit timbangan digital kepada kelompok pengrajin, sebagai solusi untuk mempercepat proses produksi, dalam rangka meningkatkan hasil produksi keripik pisang.

7. Melakukan demo operasional penirisan minyak dengan menggunakan mesin spinner yang dilakukan oleh tim dan penirisan minyak dengan cara manual oleh pengrajin, yang diikuti oleh seluruh anggota kelompok pengrajin keripik pisang, bertempat di salah satu rumah pengrajin keripik pisang Desa Galengdowo.

8. Mencatat waktu yang dibutuhkan untuk proses penirisan dengan cara manual maupun dengan menggunakan mesin spinner.

Dari data waktu penirisan yang diperoleh baik secara manual maupun dengan menggunakan mesin spinner, selanjutnya dilakukan perhitungan dan analisa, untuk menghitung kapasitas produksi, berdasarkan waktu tiris dan massa keripik.

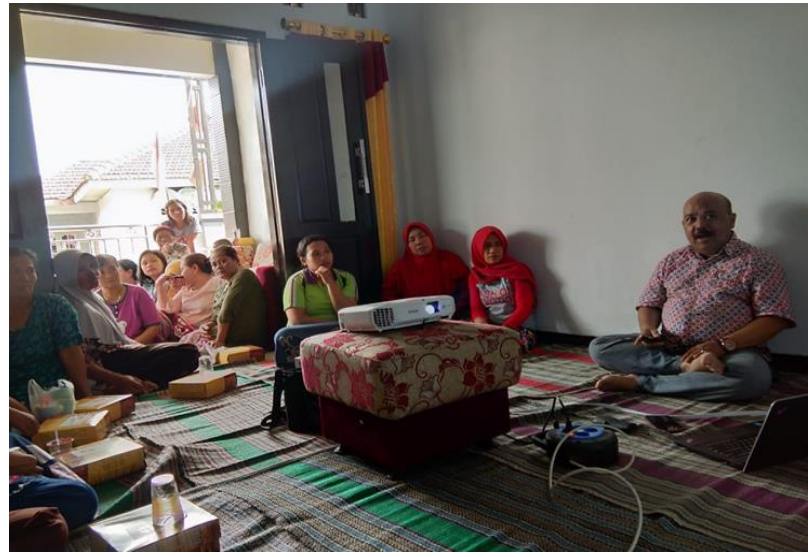

Gambar 3. Presentasi Penyuluhan Mesin Peniris Minyak Kepada Para Pengrajin

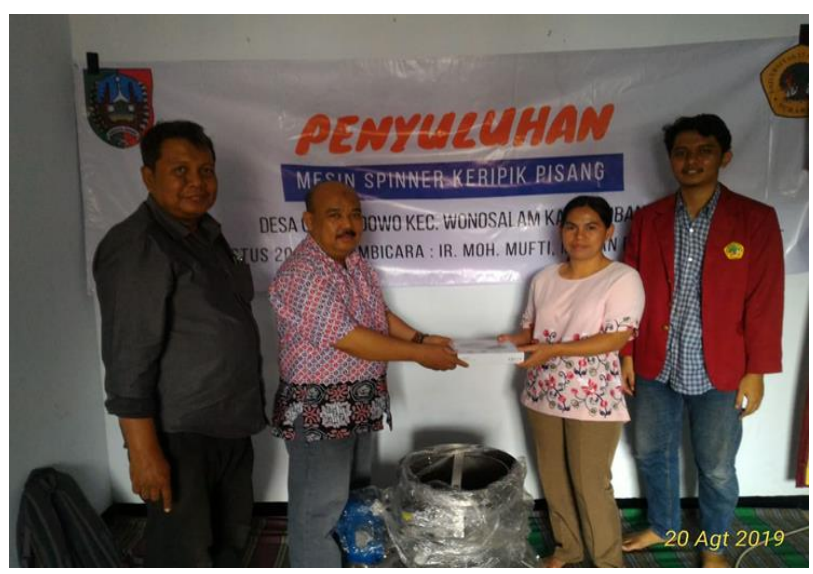

Gambar 4. Serah Terima Mesin Peniris Minyak (spinner) Kepada Kelompok Pengrajin

\section{HASIL DAN PEMBAHASAN}

Prinsip kerja dari TTG mesin peniris minyak ini adalah memanfaatkan putaran dari drum peniris minyak yang diputar oleh motor melalui poros pemutar drum. Akibat dari putaran drum peniris tersebut, akan menimbulkan gaya sentrifugal. Dimana gaya sentrifugal inilah yang melemparkan keripik yang sudah digoreng pada bagian sisi dinding drum peniris, yang seluruh permukaannya berlubang. Melalui lubang-lubang inilah minyak akan terlempar keluar menuju drum cover penampung minyak. Untuk selanjutnya minyak hasil tirisan dikeluarkan melalui saluran keluar. Gaya sentrifugal yang terjadi pada drum peniris minyak ini, dapat dijelaskan seperti gerak melingkar (putar) dari sebuah partikel (bola) seperti pada gambar 5 


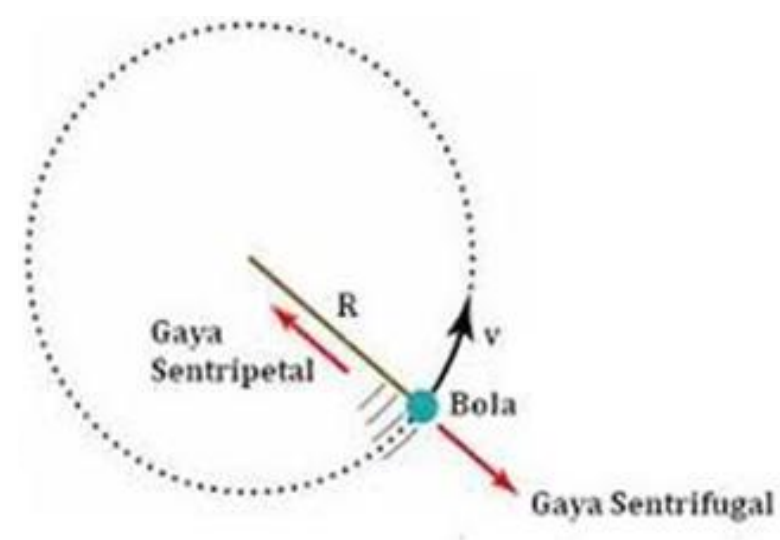

Gambar 5. Gerak melingkar partikel

Sebuah partikel (bola) yang bergerak melingkar (rotasi) seperti pada gambar 3 diatas, akan timbul gaya sentrifugal yang arahnya meninggalkan pusat putaran, dimana besarnya gaya sentrifugal $(\mathrm{Fs})$ adalah sbb:

$\mathbf{F s}=\mathbf{m}$. $\mathbf{a}$

dimana:

$\mathrm{Fs}=$ gaya sentrifugal $(\mathrm{N})$

$\mathrm{m}$ = massa partikel (bola) $(\mathrm{kg})$

$\mathrm{a}=$ pecepatan sentrifugal bola $\left(\mathrm{m} / \operatorname{det}^{2}\right)$

$\mathrm{a}=\frac{v^{2}}{R}$

$\mathrm{v}=$ kecepatan linier bola $(\mathrm{m} / \mathrm{det})$

$\mathrm{v}=\omega . \mathrm{R}$

$\mathrm{a}=\omega^{2} . \mathrm{R}$

$\mathrm{R}=$ jari- jari lintasan lingkaran bola (m)

$\omega=$ kecepatan sudut putaran (rad/det)

$=\frac{2 \pi n}{60}$

$\mathrm{n}$ = putaran bola $(\mathrm{rpm})$

Sehingga persamaan (1), menjadi:

$\mathrm{Fs}=\mathrm{m} \cdot \omega^{2} \cdot \mathrm{R}$

$F_{s}=m \cdot(2 \pi \cdot n / 60)^{2} \cdot R$.

Persamaan (3) diatas, adalah persamaan yang menggambarkan besarnya gaya sentrifugal (gaya penirisan) yang terjadi pada mesin spinner saat penirisan minyak goreng dilakukan. Dimana besarnya gaya sentrifugal ini adalah merupakan fungsi massa keripik yang ditiriskan dan putaran drum peniris minyak. Makin besar massa keripik dan makin tinggi putaan drum, maka makin besar pula gaya sentrifugal (gaya penirisan) yang terjadi, sehingga produk keripik akan makin kering. Demikian juga berlaku sebaliknya. Namun demikian untuk penirisan keripik pisang, besar kecilnya gaya penirisan itu didasarkan pada kekerasan keripik pisang itu sendiri, agar saat proses penirisan pada mesin spinner, keripik harus kering, tetapi juga tidak hancur.
Besarnya waktu penirisan setiap kilogram keripik pisang, dapat dihitung dengan menggunakan rumus sbb:

$\mathbf{T}=\frac{\mathbf{t}}{\mathbf{m}}$

dimana:

$\mathrm{T}=$ waktu penirisan per kilogram (menit $/ \mathrm{kg})$

$\mathrm{t}=$ waktu penirisan (menit)

$\mathrm{m}=$ massa keripik $(\mathrm{kg})$

Sedangkan untuk menghitung kapasitas penirisan dapat dihitung dengan menggunakan rumus sbb:

$\mathrm{Q}=\frac{\mathrm{m}}{\mathrm{t}}$

dimana:

$\mathrm{Q}=$ Kapasitas penirisan $(\mathrm{Kg} / \mathrm{menit})$

$\mathrm{m}=$ Massa keripik $(\mathrm{Kg})$

$\mathrm{t}=$ Waktu penirisan (menit) an sbb:

Dari persamaan (4) dan (5) diperoleh hubung-

$\mathbf{T}=\frac{1}{\mathbf{Q}}$

Dari persamaan (6) dapat dilihat, bahwa hubungan antara kapasitas penirisan dengan waktu penirisan per kilogram berbanding terbalik. Artinya, makin besar kapasitas penirisannya, maka waktu penirisan per kilogram akan semakin kecil, demikian pula sebaliknya.

Dari hasil demo pencatatan waktu penirisan yang dilakukan dengan cara manual maupun dengan menggunakan mesin spinner, hasilnya tersaji seperti pada tabel 1 .

Tabel 1. Lama waktu penirisan

\begin{tabular}{ccccc}
\hline & \multicolumn{2}{c}{ Cara manual } & \multicolumn{2}{c}{ Mesin spinner } \\
\cline { 2 - 5 } No. & $\begin{array}{c}\text { Massa } \\
\text { keripik (kg) }\end{array}$ & $\begin{array}{c}\text { Waktu } \\
\text { (menit) }\end{array}$ & $\begin{array}{c}\text { Massa } \\
\text { keripik (kg) }\end{array}$ & $\begin{array}{c}\text { Waktu } \\
\text { (menit) }\end{array}$ \\
\hline 1. & 0,5 & 4 & 2 & 0.5 \\
2. & 0,5 & 4 & 2 & 0.5 \\
3. & 0,5 & 4 & 2 & 0.5 \\
\hline
\end{tabular}

Dari data lama waktu penirisan yang dilakukan, sebagaimana pada tabel 1 di atas akan dapat dihitung lama waktu penirisan yang dibutuhkan baik menggunakan cara manual maupun dengan menggunakan TTG mesin spinner peniris munyak.

Untuk perhitungan kapasitas penirisan diperoleh dari persamaan (5) sbb:

\section{Cara Manual}

$\mathrm{Q}=\frac{\mathrm{m}}{\mathrm{t}}=\frac{0,5}{4}=0.125 \mathrm{~kg} / \mathrm{menit}$

\section{Mesin Spinner}

$\mathrm{Q}=\frac{\mathrm{m}}{\mathrm{t}}=\frac{2}{0,5}=4 \mathrm{~kg} / \mathrm{menit}$ 
Sedangkan untuk menghitung waktu penirisan per kilogram keripik dapat digunakan persamaan (6) sbb:

\section{Cara Manual}

$\mathrm{T}=\frac{\mathbf{1}}{\mathbf{Q}}=\frac{1}{0,125}=8 \mathrm{menit} / \mathrm{kg}$

$$
\begin{aligned}
& \text { Mesin Spinner } \\
& \mathrm{T}=\frac{\mathbf{1}}{\mathbf{Q}}=1 / 4=0,25 \mathrm{menit} / \mathrm{kg}
\end{aligned}
$$

Dari hasil perhitungan tersebut diatas, dapat dilihat bahwa waktu tiris minyak per kilogram keripik dengan menggunakan mesin spinner jauh lebih cepat dibandingkan dengan menggunakan cara manual sehingga kapasitas produksi yang dihasilkan jika menggunakan mesin spinner akan menjadi jauh lebih besar.

\section{SIMPULAN DAN REKOMENDASI}

Dari hasil analisa dan pembahasan diatas, maka dapat disimpulkan sebagai berikut:

1. Mesin spinner keripik pisang mempunyai waktu penirisan 32 kali lebih cepat dibandingkan dengan peniris manual.
2. Dengan menggunakan mesin spinner, proses produksi dapat dipercepat.

3. Dengan menggunakan mesin spinner, kapasitas produksi keripik pisang dapat ditingkatkan sampai 32 kali lipat dibandingkan dengan menggunakan peniris manual.

4. Dengan menggunakan mesin spinner akan dapat mengurangi biaya operasional

5. Dengan menggunakan mesin spinner, keuntungan yang diperoleh pengrajin akan menjadi lebih besar.

6. Disarankan agar pengrajin selalu menggunkan mesin spinner, setiap kali melakukan penirisan.

\section{DAFTAR PUSTAKA}

Aaron D. Deutschman, Machine Design, Macmillan Publishing Co. Inc., 1975

J.L. Meriam, L.G. Kraige, Engineering Mechanics, Dynamics, John Wiley and Sonds Inc, 1997

Gergorge H. Martin, Terjemahan Ir. Setyobakti, Kinematika dan Dinamika Mesin, Erlangga, Jakarta, 1984

Keith M. Walker, Applied Mechanics for Engineering Technology, Eight Edition, Prantice Hall, 2008 